\title{
BUDAYA MULUT DAN TANGAN SEHAT PADA ANAK USIA SEKOLAH DASAR DI DESA MAMBEN DAYA KECAMATAN WANASABA KECAMATAN LOMBOK TIMUR
}

\author{
Eva Triani*1, Indana Eva Ajmala'2, Ika Primayanti ${ }^{3}$, \\ Dinie Ramdhani Kusuma ${ }^{4}$, Putu Suwitasari ${ }^{1}$ \\ ${ }^{1,5}$ Department of Parasitology, Medical Faculty of Mataram University \\ ${ }^{2}$ Department of Pulmonology, Medical Faculty of Mataram University \\ ${ }^{3}$ Department of Public Health, Medical Faculty of Mataram University \\ ${ }^{4}$ Department of Dermathology and Venereologi, Medical Faculty of Mataram University
}

Kata Kunci:

Kecacingan, Murid Sekolah Dasar, Pesisir pantai

\begin{abstract}
Abstrak: Latar Belakang : Kecacingan merupakan penyakit menular yang masih menjadi masalah kesehatan masyarakat di Indonesia karena berjangkit di sebagian besar wilayah Indonesia dan dapat mengakibatkan menurunnya kondisi kesehatan, gizi, kecerdasan dan produktifitas Faktor-faktor yang berhubungan dengan infeksi cacing pada anak erat hubungannya dengan hygine dan sanitasi.Infeksi ini berdampak buruk terhadap perkembangan kesehatan.

Tujuan dan metode: Untuk meningkatkan derajat kesehatan anak-anak di tingkat Sekolah Dasar dengan cara meningkatkan pengetahuan tentang kecacingan dan upaya pencegahannya melalui edukasi terkait faktor-faktor yang menjadi penyebab penyakit kecacingan serta upaya yang dapat dilakukan secara perorangan dalam rangka pemberantasan penyakit kecacingan.

Hasil : Angka kejadian kecacingan pada murid SD di pesisir pantai Ampenan mencapai $31,3 \%$. Terdiri dari 20,87\% Trichuriasis, 4,35\% Ascariasis dan 6,09\% infeksi campuran.Tingkat pengetahuan tentang kecacingan terbagi menjadi baik (B) $87,7 \%$ dan buruk (K) $12,3 \%$

Kesimpulan: Prevalensi Kecacingan pada murid Sekolah Dasar di daerah pesisir pantai Ampenan masih dalam kategori tinggi. Hal ini dapat disebabkan karena faktor kebersihan perorangan yang masih rendah
\end{abstract}

Korspodensi email: evatriannisa@gmail.com

\section{PENDAHULUAN}

Anak sekolah merupakan aset atau modal utama pembangunan di masa depan yang perlu dijaga, ditingkatkan, dan dilindungi kesehatannya. Salah satu permasalahan yang dialami anak sekolah dasar yang patut menjadi perhatian adalah masalah kesehatan. Kesehatan merupakan suatu modal penting bagi sang anak untuk menjalani kehidupannya dalam mencapai tujuan sebagai agen pembangunan nasional kedepannya. Dengan terlindunginya anak dari berbagai permasalahan kesehatan, maka ia akan mudah untuk menyerap segala pelajaran yang ia dapatkan pada masa sekolah dasar ini. Namun, jika tidak, anak akan sulit untuk menyerap segala hal yang ia dapatkan dalam proses belajarnya. Memang, masalah kesehatan yang dialami anak pada masa sekolah dasar sangatlah banyak. Namun, yang patut menjadi perhatian adalah masalah infeksi kecacingan (Gandahusada et al, 2004). Hal ini karena infeksi kecacingan merupakan penyakit infkesi yang paling sering diderita anak sekolah dasar. Infeksi kecacingan merupakan salah satu penyakit yang sering diderita oleh anak-anak, khususnya anak sekolah dasar, dengan persentase mencapai 40-60\% dari seluruh penyakit yang dialami anak sekolah dasar ( WHO , 2013). 
Penyakit kecacingan distribusinya tersebar secara luas, baik di pedesaan maupun di perkotaan. Angka infeksinya tinggi, tetapi intensitas infeksi (jumlah cacing dalam perut) berbeda (Kemenkes RI, 2012). Hasil survei infeksi kecacingan pada murid sekolah dasar di beberapa provinsi pada tahun 1986-1991 menunjukkan prevalensi sekitar 60\%-80\%, sedangkan untuk semua umur berkisar antara 40\%-60\% (Kartini S, 2016).

Hasil survei Depkes pada tahun 2011, menunjukkan bahwa prevalensi kecacingan di Kabupaten Lombok Barat mencapai angka 29,47\%. Angka ini termasuk tinggi dan menempati peringkat ke-5 dari hasil survei yang telah dilakukan pada beberapa kabupaten di Indonesia (Riskesdas, 2013). Murid sekolah dikatakan sebagai salah satu penderita penyakit kecacingan yang prevalensi dan insidensinya tinggi, dikarenakan usia anak sekolah memiliki bayak faktor resiko terinfeksi penyakit kecacingan, mulai dari faktor bermain anak, kebersihan diri, kebersihan lingkungan, kebiasaan mencuci tangan sebelum makan, tingkat pendidikan orang tua dan kurangnya perhatian orang tua

\section{METODE KEGIATAN}

Kegiatan pengabdian masyarakat ini dilaksanakan dalam bentuk penyuluhan kesehatan mengenai kecacingan dan upaya pencegahannya. Selain itu juga dilakukan pemeriksaan feses pada siswa sekolah dasar untuk mendeteksi penyakit kecacingan sehingga segera dilakukan upaya pengobatannya

\section{HASIL DAN PEMBAHASAN}

Kegiatan ini diikuti oleh murid-murid Sekolah Dasar Negeri 47 Ampenan yang keseluruhan berjumlah 68 orang. Hasil pemeriksaan feses menunjukkan angka kejadian kecacingan mencapai 31,3\%. Terdiri dari 20,87\% Trichuriasis, 4,35\% Ascariasis dan 6,09\% infeksi campuran.Tingkat pengetahuan tentang kecacingan terbagi menjadi baik (B) $87,7 \%$ dan buruk (K) $12,3 \%$

Kegiatan penyuluhan berjalan dengan lancar. Para siswa sangat antusias untuk berpartisipasi dalam kegiatan penyuluhan ini, agar nantinya mereka dapat berbagi pengetahuan dengan teman-teman sebaya mereka terutama mengenai materi penyuluhan tersebut yaitu tentang penyakit kecacingan dan merubah sikap serta perilaku mereka ke arah yang lebih baik. Kepala Sekolah dan juga para guru juga sangat mendukung adanya kegiatan ini. Hal ini terlihat dengan kesediannya untuk memfasilitasi tempat dan perlengkapan untuk pelaksanaan kegiatan pengabdian kepada masyarakat tersebut.

Dari kegiatan yang tersebut, dapat diketahui tingkat pengetahuan para siswa tentang penyakit kecacingan pada awalnya cukup rendah sehingga dengan kegiatan pengabdian kepada mayarakat melalui penyuluhan tentang kecacingan ini diharapkan pengetahuan para murid dan juga pendidik di sekolah semakin meningkat, serta dapat merubah sikap dan perilaku mereka ke arah yang baik mengenai kesehatan mereka. Para murid juga dapat sekaligus melakukan pemeriksaan dan pengobatan serta berkonsultasi mengenai kesehatan mereka pada kegiatan ini. 
Para murid yang dari hasil pemeriksaan menunjukkan terinfeksi kecacingan selanjutnya juga mendapatkan pengobatan,serta bagi yang tidak terinfeksi kecacingan akan mendapatkan pengobatan untuk pencegahan.
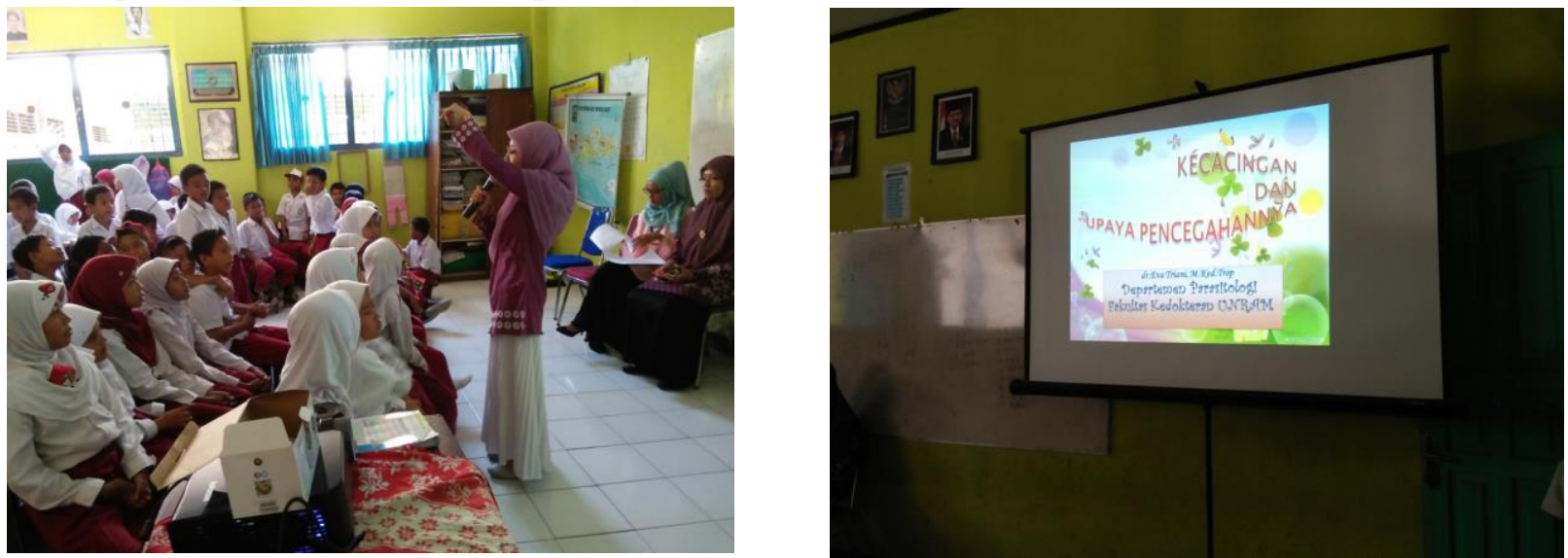

Gambar 1. Penyuluhan Kecacingan

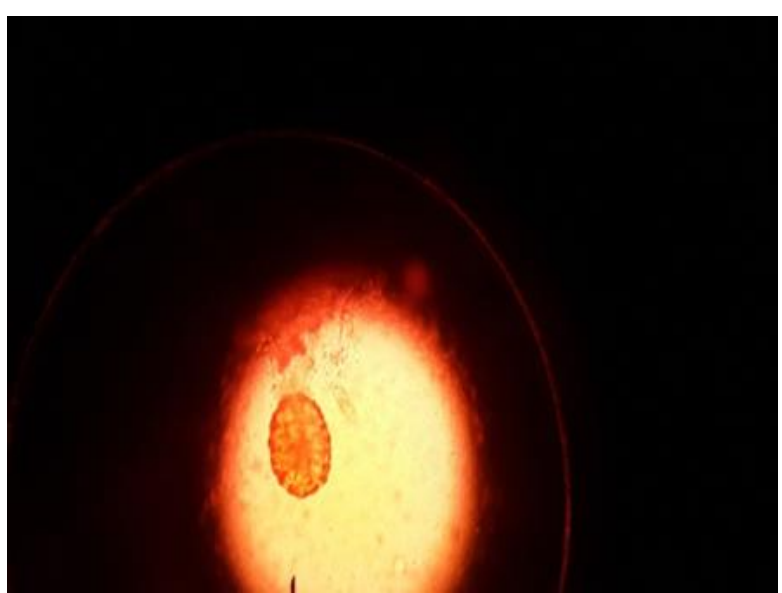

a.Telur Ascaris Lumbricoides

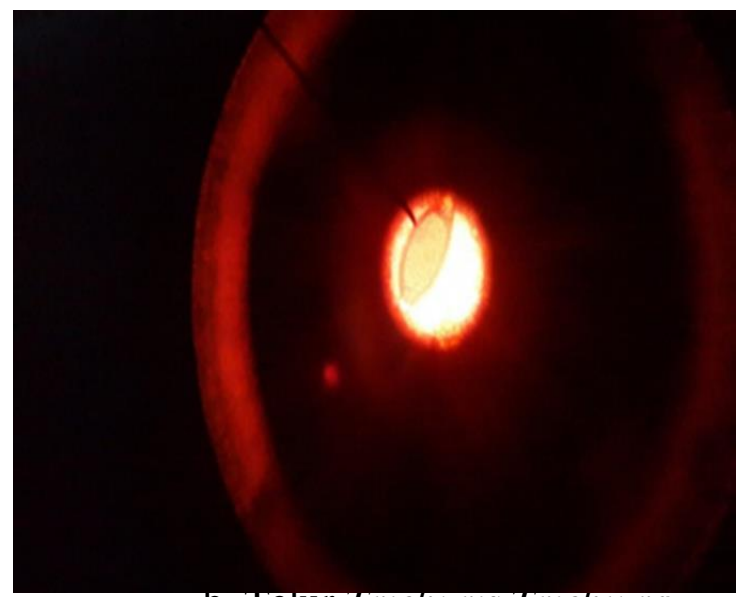

b. Ielur Irlchurls Irlchlura

Gambar 2. Hasil pemeriksaan feses yang mengandung telur cacing

\section{KESIMPULAN DAN SARAN}

Berdasarkan hasil kegiatan dan evaluasi yang telah dilakukan, dapat diambil beberapa kesimpulan yaitu

- Tingkat pengetahuan para murid tentang penyakit kecacingan sebelum adanya kegiatan Penyuluhan ini masih cukup rendah, hal ini terlihat pada hasil kuesioner awal yang diberikan sebelum kegiatan dimulai.

- Dengan adanya kegiatan Penyuluhan tentang kecacingan dan upaya pencegahannya terdapat adanya peningkatan pengetahuan para siswa, hal ini terlihat pada hasil kuesioner akhir.

- Hasil pemeriksaan feses menunjukkan angka kejadian kecacingan mencapai 31,3\%. Terdiri dari 20,87\% Trichuriasis, 4,35\% Ascariasis dan 6,09\% infeksi campuran.

- Tingkat pengetahuan tentang kecacingan terbagi menjadi baik sebesar $87,7 \%$ dan buruk sebesar $12,3 \%$ 
Kegiatan penyuluhan kesehatan terutama tentang kecacingan perlu untuk terus dilakukan, disamping itu juga perlu dilakukan pemeriksaan kesehatan secara umum dan konsultasi kesehatan sehingga para murid sekolah dasar serta para guru untuk dapat berperilaku yang baik terutama dalam hal higienitas personal dan menjaga lingkungan mereka agar tetap sehat.

\section{UCAPAN TERIMA KASIH}

Terima Kasih kami sampaikan kepada Universitas Mataram yang telah memberikan dukungan finansial dalam kegiatan Pengabdian Kepada Masyarakat ini melalui dana DIPA BLU (PNBP)

\section{DAFTAR PUSTAKA}

Gandahusada, S., Ilahude, H.H.D., \& Pribadi, W. 2004. Parasitologi Kedokteran Edisi Ketiga. Balai Penerbit FKUI. Jakarta

Kartini S.2016. Kejadian kecacingan pada Siswa sekolah Dasar Negeri Kecamatan Rumbai Pesisir Pekanbaru. Jurnal Kesehatan Komunitas.Volume 3

Kementerian Kesehatan RI Direktorat Jenderal PP dan PL Subdit Pengendalian Penyakit dan Penyehatan Lingkungan. 2012. Pedoman Pengendalian Kecacingan. Jakarta

Riset Kesehatan Dasar (Riskesdas). 2013. Badan Penelitian Dan Pengembangan Kesehatan, Kementerian Kesehatan RI. Konsep Dan Penulisan Riset Keperawatan. Graha Ilmu : Jakarta.

World Health Organization (WHO). 2013. Soil Transmitted Helminthes. Intestinal Worms [online]. Available at: (http://www.who.int/intestinal worms/en/).Diakses tanggal 24 Juni 2019. 